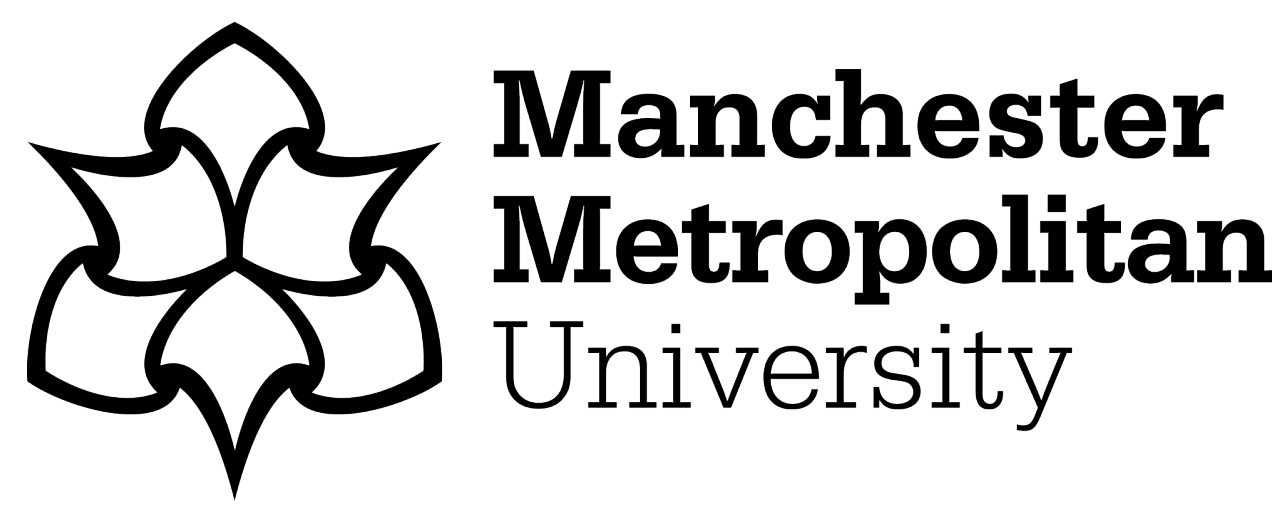

Lawlor," M-A, Dunne, A and Rowley, JE ORCID logoORCID: https://orcid.org/0000-0003-3437-6914 (2016) Young consumers' brand communications literacy in a social networking context. European Journal of Marketing, 50 (11). pp. 2018-2040. ISSN 1758-7123

Downloaded from: https://e-space.mmu.ac.uk/10/

Version: Accepted Version

Publisher: Emerald

DOI: https://doi.org/10.1108/EJM-06-2015-0395

Please cite the published version 


\section{Young Consumers' Brand Communications Literacy in a Social Networking Site Context}

\begin{tabular}{|r|l|}
\hline Journal: & European Journal of Marketing \\
\hline Manuscript ID & EJM-06-2015-0395.R1 \\
\hline Manuscript Type: & Original Article \\
\hline Keywords: & $\begin{array}{l}\text { Children, Advertising literacy, Social networking sites, Paid, owned, earned } \\
\text { media }\end{array}$ \\
\hline \multicolumn{2}{|l}{} \\
\hline
\end{tabular}




\title{
Young Consumers' Brand Communications Literacy in a Social Networking Site Context
}

\begin{abstract}
Purpose - Whilst substantial scholarly attention has been given to children's understanding of advertising in the context of traditional advertising channels, there is a gap in the literature with regard to children's commercial awareness in the context of online social networking sites (SNS). This paper seeks to explore the nature and extent of advertising literacy amongst young consumers in the context of their use of SNS, namely Facebook and Bebo.

Design/methodology/approach - A three-stage study was conducted with 12-14 year old girls, using focus group discussions, participant observation and in-depth interviews.

Findings - The study illustrates that the increasingly blurred line between online advertising and other forms of online brand-related content is militating against the development of advertising and marketing literacy in young consumers. A key issue which is discussed is the extent to which the traditional conceptualisation of advertising literacy is 'fit for purpose' in an online context.

Originality/value -The authors propose an alternative to the advertising literacy concept, namely the Online Brand Communications (OBC) literacy framework. This framework recognises the convergence of traditional online advertising and other forms of online brand content, and also acknowledges that the messaging around a brand may originate from the brand owner in a variety of overt and covert forms. Equally, online consumers may also act as brand promoters when they engage in brand-related word-of-mouth.
\end{abstract}

Key words: Children, Advertising literacy, Social networking sites, Paid, owned, earned media

Paper type: Research paper 


\section{Introduction}

A child's ability to discern and examine advertising messages in a conscious and evaluative manner has long been identified as a critical issue for academic, practitioner and regulatory attention (Shin, Huh and Faber, 2012; Rozendaal, Buijzen and Valkenburg, 2011; Friestad and Wright, 2005). However, a new dimension to the child-advertising debate has emerged as children increasingly embrace newer online platforms, such as interactive games, social networking sites and branded websites (An and Kang, 2013; Dahl, Eagle and Báez, 2009). Whilst there is a substantial body of research exploring children's understanding of advertising in the context of traditional advertising channels such as television, there has been a much smaller stream of research exploring the nature of advertising understanding in an online context. Specifically, there is a significant research gap regarding children's interaction with commercial content in the context of social networking sites (SNS). Children's recognition and understanding of how they can be targeted for commercial purposes by online marketers, is an important and pressing area for research for a number of reasons.

Firstly, children are prolific users of SNS. For example, in the UK, Ofcom (2014) identify that $67 \%$ of children, aged between $12-15$ years of age, had an active SNS profile in 2013. In the US, more than $60 \%$ of $13-17$ year olds have at least one profile on a SNS (American Academy of Child and Adolescent Psychiatry, 2011).

Secondly, the nature of marketing communications in SNS and in other online platforms differs from traditional media contexts. A TV advertisement might have a duration of thirty seconds to capture a child's attention and the viewer's response to that ad may be passive 
(Moore and Rideout, 2007). On the other hand, online platforms such as SNS and advergames encourage children's active input over a longer period of time. This interaction is characterised by the nature of play and entertainment whereby recognisable brand characters and other brand imagery are embedded into the content (Schwartz, Kunkel and DeLucia, 2013; Shin, Huh and Faber, 2012). For example, advergames offer "a form of branded entertainment that feature advertising messages, logos, and trade characters in a game format" (Mallinckrodt and Mizerski, 2007, p.87). The outcome is that the integration of brand messages into such online platforms may lead to a blurring of the boundaries between entertainment and marketing content (Cheyne, Dorfman, Bukofzer and Harris, 2013).

Finally, children's advertising literacy in a SNS context has not been previously explored in the academic literature. The theme of this special issue of the European Journal of Marketing pertains to the impact of marketing on children's well-being in a digital age. Yet, children are particularly vulnerable in the face of the interactive, subtle and engaging nature of nontraditional practices that have emerged due to rapid advances in technology (e.g. Freeman and Shapiro, 2014; Panic, Cauberghe and De Pelsmacker, 2013; Mallinckrodt and Mizerski, 2007). Therefore, it is important to develop an understanding of children's advertising nous in non-traditional contexts such as SNS, where a brand's commercial presence may be more seamlessly integrated into online content and platforms.

Accordingly, this paper presents findings from an Irish study whose primary aim was to explore the nature and extent of advertising literacy amongst 12-14 year old girls, in the context of their use of online SNS. Specifically, the first objective was to investigate the participants' awareness and understanding of the range of forms of commercial content within the SNS that they were using. The second objective was to explore their ability to 
employ such knowledge in a critical manner, namely their ability to filter and critically evaluate such commercial messages. The paper is structured as follows. An examination is provided of the literature relating to advertising literacy amongst children, and subsequently, the convergence of traditional online advertising and other forms of online brand content. The paper then explores the interpretivist, qualitative approach and methodology which informed the study before proceeding to a discussion of the research findings. The authors propose an alternative to the advertising literacy concept for specific application in an online context, namely the Online Brand Communications (OBC) literacy framework. The conclusion section considers the significance of these findings, and offers suggestions for further research and directions for public policy and practice in the area.

\section{Theoretical Background}

\section{Advertising Literacy in Children}

The pressing requirement for children to develop and hone advertising literacy skills has been noted in the literature (e.g. Eagle, 2007; O'Sullivan, 2007). Advertising literacy has been broadly defined in terms of a person's understanding of advertising (e.g. Young, 2000). More specifically, Rozendaal, Lapierre, Van Reijmersdal and Buijzen (2011) identify seven components of advertising literacy - recognition of advertising as a genre, recognition of the advertiser as the message source, understanding of the audience as an advertising target, understanding of the selling intent of advertising, understanding of the persuasive intent of advertising, understanding of the persuasive tactics used by the advertiser, and finally, understanding of the potential for bias in advertising. These components are also reflected in Buckingham's (1993) explanation of children's advertising literacy, namely, their ability to be cynical of advertising claims arising from their recognition of the selling intent behind the advertisement and, in addition, the child's ability to be critical of the aims and execution of 
the advertisement. Elsewhere, Ritson and Elliott (1995) parse the concept of literacy into the ability to co-create and act upon advertising's multifarious meanings. Therefore, knowledge and understanding of advertising constitutes one dimension of literacy, but a further question relates to the extent to which children subsequently retrieve and employ such knowledge as a filter or defence against advertising (e.g. Verhellen, Oates, De Pelsmacker and Dens, 2014; Rozendaal, Lapierre, Van Reijmersdal and Buijzen, 2011; Young, 2003).

It is proposed that as children move from the stages of early childhood to adolescence, they gradually develop the ability to (a) discern between advertising and other genres of communication, (b) develop a more sophisticated understanding of advertising's persuasive intent and (c) develop recognition of a commercial agenda or bias (Lawlor and Prothero, 2008; Moore and Rideout, 2007). From a consumer socialisation perspective, the emergence of this understanding helps children to navigate the commercial world (Kerrane and Hogg, 2013; Ward, 1974). However, the development of such knowledge is predicated on the child's information-processing abilities (Boush, Friestad and Rose, 1994). For example, in terms of stages of child development, it has been suggested that children aged up to seven years, are 'limited processors' of incoming information in that they have not yet developed efficient information processing faculties (Roedder 1981), and tend towards a basic and egocentric approach to the world around them (Selman, 1980). By the age of approximately eight years, children can identify the persuasive intent of advertising and distinguish it from informational content (Roedder John, 1999), and by the age of 12 years, children can exhibit a critical and even sceptical understanding of advertising and its intentions. In this regard, Roedder John (1999) refers to the age span of 11 to 16 years as being a reflective stage. Herein, young consumers ostensibly develop sophisticated information processing skills, which can assist them in becoming more aware of the views of other people, as well as 
developing a more nuanced knowledge of the commercial landscape. As such, a child's ability to recognise persuasive intent and ergo, commercial bias in advertising, can lead to the development of scepticism towards advertising (Moore and Rideout, 2007).

The principal model that has been used to explain the development of a consumer's knowledge in this area is Friestad and Wright's (1994) Persuasion Knowledge Model (PKM) (see An, Jin and Park, 2014; Newman and Oates, 2014; Panic, Cauberghe and De Pelsmacker, 2013). The PKM offers a theoretical lens to understand how consumers can, over time, develop persuasion knowledge which facilitates an understanding of marketing / advertising tactics that may be employed by marketers. A related form of knowledge illustrated in the PKM is that of agent knowledge which relates to an understanding of the advertiser and his/her objectives and competencies. This knowledge will in turn act as a defence that the consumer can employ against advertising, e.g. in terms of evaluating and discounting a commercial message (Friestad and Wright, 1994). However, as will be examined in the next section, a child's ability to distinguish the presence of the agent and to develop and deploy persuasion knowledge may be challenged or indeed militated against, in the light of the immersive and entertaining nature of online platforms such as SNS and advergames (Schwartz, Kunkel and DeLucia, 2013; Shin, Huh and Faber, 2012; Moore and Rideout, 2007).

\section{Children's Advertising Literacy in an Online Context}

It is observed that the traditional approach to exploring advertising literacy has been to focus on children's ability to discern between advertising and other media platforms (e.g. television programmes), and their capacity to understand the advertiser's commercial intent (Rozendaal, 
Buijzen and Valkenburg, 2011; Livingstone and Helsper, 2006; Young, 2000; Roedder John, 1999). In contrast, children's interaction with the commercial guise of the online environment has received very little attention in the literature. For example, Freeman and Shapiro (2014) refer to a gap in scholarly understanding of young people's awareness of, and coping strategies for, marketing practices in the online environment. Elsewhere Shin, Huh and Faber (2012, p.734) highlight the "considerable lack of knowledge" pertaining to how children respond to online advertising whilst more specifically, Clarke and Svanaes (2012) observe the gap that prevails with regard to research into children's interaction with advertising within SNS. Equally, the requirement to understand how children process and experience brands in the context of the influential role of the internet in tandem with traditional forms of advertising media has been noted in the literature (e.g. Verhellen, Oates, De Pelsmacker and Dens, 2014; Nairn, Griffin and Wicks, 2008; Moore and Rideout, 2007).

Children are increasingly embracing non-traditional platforms such as interactive games, social networking sites and branded websites (An and Kang, 2013; Livingstone, Ólafsson, and Staksrud, 2013; Panic, Cauberghe and De Pelsmacker, 2013; Grimes and Shade, 2005). Specifically, these online platforms differ from traditional media in that they seek to offer children the facility for play, entertainment and immersion in the overall experience over a longer period of time (Schwartz, Kunkel and DeLucia, 2013; Shin, Huh and Faber, 2012). A widely expressed concern in the literature is that the embedded, interactive and entertaining capabilities of online platforms can lead to commercial messages exerting more subtle and persuasive effects on children, who also may not be fully aware of the nature and purpose of these commercial messages (Owen, Lewis, Auty and Buijzen, 2013; Nairn and Hang, 2012; Rozendaal, Buijzen and Valkenburg, 2011; Mallinckrodt and Mizerski, 2007). 
To return to the Persuasion Knowledge Model (Friestad and Wright, 1994), if marketers are using subtle or covert tactics to market to children, it follows that the development of agent knowledge (i.e. "this brand is seeking to target me") and persuasion knowledge (i.e. "these are the means by which the brand is seeking to change my behaviour") may be challenged in light of the immersive and entertaining nature of online platforms such as SNS and advergames (Schwartz, Kunkel and DeLucia, 2013; Shin, Huh and Faber, 2012). This is because children's attention may be turned to compelling online content as opposed to deploying cognitive skills to evaluate commercial messages (Nairn and Fine, 2008; Moore and Rideout, 2007; Grimes and Shade, 2005).

\section{Commercial Presence on Social Networking Sites}

There is a growing body of literature relating to the role of SNS in children's lives and children's specific uses of SNS. For example, a number of authors (Clarke, Goodchild and Harrison, 2010; Willett, 2009; Boyd, 2007) have variously identified that young people (ranging in age from eight to 18 years) engage in SNS behaviours such as profile decoration and game-playing for the purposes of entertainment and the alleviation of boredom. The literature has also acknowledged that a key motivation is that of identity management (Anderson and McCabe, 2012; Stern, 2008; Willett, 2008). For example, Livingstone and Brake (2010) observe that teenagers' use of SNS is motivated by a wish to present a positive identity that wins the social validation of one's peers. In a marketing context, this can be facilitated by young consumers' publicly stated allegiances to well-known brands on their SNS profile (Willett, 2009).

However, the commercialisation of SNS has been examined more so, from the marketer's perspective and a research gap has been identified in the literature with regard to children's 
interaction with advertising within SNS (Clarke and Svanaes, 2012). In this respect, Kelly, Kerr and Drennan's (2010) study examined teens' perceptions of, and attitudes towards advertising on social networking sites. The teenagers were of the opinion that advertising assumed the form of banners and pop-ups only. They also felt they were capable of avoiding advertisements in the form of pop-ups and banners, and in virtually all cases, they outlined that they did take action to specifically avoid all such advertising. Elsewhere, Diffley, Kearns, Bennett and Kawalek's (2011) research with young SNS users (aged 14-17 years) illustrated how the users felt that there was an excessive commercialisation to SNS, and irritation and irrelevance factors were strongly cited with regard to pop-up ads and banner ads. It is observed that these studies focused on recognisable forms of paid-for, online advertising.

However, paid media accounts for only one aspect of the paid, earned and owned media approach to marketing (Stephen and Galak, 2012). The application of advertising literacy to date has focused on well-established and recognisable forms of advertising, namely paid media formats such as search, display ad networks or affiliate marketing whereby the brand owner invests in various online platforms to promote a given brand (Chaffey, 2012). Owned media refer to platforms that are the property of the brand, such as an organisation's own website, blogs, apps or SNS presence (Chaffey, 2012). Earned media refers to the generation of word-of-mouth communications by external interests such as consumers or journalists (Stephen and Galak, 2012). An example of this would be child members of a given website being encouraged to invite their peers to join the site (Cheyne, Dorfman, Bukofzer and Harris, 2013) whereby the children essentially become the promoters of the site. A further example of earned media would relate to the online sharing and discussion of a given 
advertisement by consumers whereby they essentially become promoters for the brand in question.

Therefore, the recognisable forms of paid advertising that have been studied to date in the context of advertising literacy, must now be considered in the context of the paid, owned, earned media (POEM) model. When considered in the context of young consumers, POEM highlights that children may be exposed to brand-related content by means other than paid advertising, and as such, there is a great deal of scope for further research into the commercial side of SNS, and specifically, the manner in which children and young teenagers are navigating this commercial content, in terms of their ability to recognise and critically evaluate it.

\section{Research Methodology}

The primary aim of this study, conducted in Ireland, was to explore the nature and extent of advertising literacy amongst 12 to 14 year old girls in the context of their use of online social networking sites. Specifically, the first objective was to investigate the participants' awareness and understanding of the forms of commercial content in the SNS that they were using. The second objective was to explore their ability to employ this knowledge in a critical manner, namely their ability to filter and critique such commercial messages. The interpretivist paradigm underpinned the study whereby the focus of the research was to provide a deeper understanding of how the girls in this study interact with the commercial guise of SNS whilst acknowledging that participants might have varying perspectives on the topic depending on their personal situation or outlook (Carson, Gilmore, Perry and Gronhaug, 2001; Denzin and Lincoln, 1998). 
Accordingly, qualitative research was undertaken, involving three stages comprising (i) fifteen focus groups, (ii) participant observation, followed by (iii) eleven in-depth interviews. In all, forty-seven girls aged between 12 and 14 years participated in this research. The choice of a female-only sample was informed by an observation that girls are more prolific users of SNS than their male counterparts (O’Neill and Dinh, 2012; Coughlan, 2010).

\begin{abstract}
All ethical guidelines concerning the conduct of research with children were strictly adhered to, including the anonymisation of the participants as well as the requirement to conduct the research in a protected environment (ESOMAR, 1999), which in this case, constituted a school setting and a sports club setting. The principle of informed consent underpinned this study. Access and permission to conduct research with the participants were sought from the parents / guardians of the participants and also from the participants themselves (Market Research Society, 2012; ESOMAR, 1999). Permission to record the discussions was sought from the participants. Also, in keeping with the Market Research Society's (2012) advice regarding the use of social networking profiles for research purposes, permission was sought from the girls for both access to their SNS pages and permission to view the content within.
\end{abstract}

With regard to the school-based research, the girls were in the same year (i.e. first year) in an all-girls secondary school in the south of Ireland. The girls were mostly aged 13-14 years, (three of the girls were aged 12 years), thereby leading to a mix of 12-14 year olds in the focus group discussions. The selection of these first-year school pupils was also informed by their recent move from primary to secondary school which resulted in the girls being in a new social environment where their quest to make new friends and retain old friends, could potentially drive their use of social networking sites. All of the girls were regular online users, citing video-sharing websites (e.g. YouTube), online auction sites (e.g. eBay) and SNS 
(e.g. Bebo and Facebook) as their preferred online platforms. It should be noted that whilst Bebo was the more popular SNS amongst the sample, eight of the girls (either aged 13 or 14 years old) were Facebook users.

The first stage of the study involved fifteen focus group discussions with all forty-seven girls regarding their usage of social networking sites, namely Facebook and Bebo. Focus groups (three to five participants per group) were deemed to reflect the free-flowing, social ambience of SNS, offering participants an opportunity to discuss their use of this online platform and their awareness of commercial content within a given site. The participants were then invited to participate in a second stage of the study, namely the participant observation (PO) stage. A defining feature of PO is its facility to allow the researcher to see and experience reality in a specific social setting, as seen and experienced by the participant (Marshall and Rossman, 2011). Therefore, to complement the focus group discussions, the PO stage was included to give the authors access to, and experience of the girls' SNS activities. The second author invited the eleven participants in this phase of the research to add her as a friend on their SNS page. This action served a number of purposes, such as providing the authors with access to the girls' profiles, particularly if the girls had their profiles set to 'private'. The act of 'friending' reaffirmed the girls' consent to participate in the research and also meant that they would be aware when their pages were being accessed, i.e. when their Bebo activities were being observed. Throughout the participant observation stage, each participant's profile page was observed on average, twice a week, over the three months.

The requirement for this stage was informed by a number of issues that emerged during the focus groups and which required further exploration. These issues related to the participants' behaviours whilst on social networking sites such as Bebo and Facebook, the relationship 
between online and offline identity, and exposure to commercial presence on SNS. Of the forty-seven girls, a total of eleven girls agreed to participate in the PO phase, giving permission for their SNS pages (specifically their Bebo pages) to be studied for a three-month period. During this time, activities on the participants' profile pages were identified, such as the posting of comments, the establishment of new friendships or group memberships, the addition of photographs and videos and the alteration of any personal information. Of especial interest was the nature of commercial content to which the participants were being subjected. For example, observations were noted regarding paid brand content (e.g. display advertising) and non-paid content such as brand-related video content, and permission-based brand communication originating from the brand's post on their own SNS page, and subsequently occurring within the user's SNS feed. At the end of the three month period, a third stage of research, namely offline interviews, was conducted with the eleven girls. The purpose of the interview component was to further discuss with the girls their rationale for maintaining a presence on a SNS, their SNS behaviours and finally, to probe their awareness and understanding of commercial presence on their SNS pages.

The social networking sites that formed the focus of this research were Facebook and Bebo. Whilst Facebook continues to dominate the social networking site environment with 936 million daily active users, on average, for March 2015 (Facebook, 2015), Bebo has experienced varying levels of popularity. For example, it was reported that Facebook was the most popular SNS (57\%) amongst young Irish users, aged 9-16 years whilst 37\% of children in Ireland used Bebo, compared to approximately $8 \%$ in the United Kingdom $\left(\mathrm{O}^{\prime}\right.$ Neill and Dinh, 2012). Bebo's inclusion in this research was a function of the fact that many of the participants were members of Bebo for parental and age-related reasons (e.g. Facebook regulations stipulate that under-thirteens are not permitted to join the site). A further 
consideration in arriving at the age-group for this study, and the focus on Facebook as well as Bebo, was the finding that half of Irish children between the ages of 9 and 16 years have a profile on at least one of the major social networking sites such as Bebo or Facebook (O’Neill, Grehan, and Ólafsson, 2011).

A number of sources of data were generated, including focus group and interview transcripts, detailed notes from the observation of the participants' Bebo activity, and records of the Bebo profile pages (e.g. screenshots) of the eleven girls who participated in the PO stage. The interviews were recorded with the girls' consent and were then transcribed and analysed. The data analysis was undertaken by immersion in the data-set which then led to the identification of emerging categories within the data (Carson, Gilmore, Perry and Gronhaug, 2001; Miles and Huberman, 1994). Categorisation and coding involved attaching a tag-word or phrase to a segment of text in order to later identify it for discussion (Kvale and Brinkmann, 2009; Miles and Huberman, 1994). The identified categories were guided by the purpose of the study, as identified by the research aim and objectives (Saunders, Lewis and Thornhill, 2009). Following the formation of categories, sections of the data were allocated to a relevant category, such as 'advertising formats'. Additionally, the categories were examined and compared with the research objectives underpinning this study. The presentation of findings utilises excerpts from the interview transcripts to support the discussion of the key themes.

\section{Discussion of Findings}

\section{Lack of Awareness of Marketing Formats}

Of the forty-seven participants who took part in this research, just under half stated that they were unaware of any forms of advertising on SNS. Those who were aware of such 
advertisements alluded to banner, pop-up or click-through advertisements. It should be noted that the participants themselves did not use these specific terms (e.g. 'pop-up', 'banner') but rather explained what they witnessed and the authors subsequently identified them as such. For example, during the individual interviews following the participant observation stage, Nicola (14 years) stated that she was aware of advertisements that "are like boxes that appear along the top of the profile pages", thus referring to banner advertisements. Additionally, Ruth (14 years) noted "there are ones [advertisements] that flash and say 'click here, you've won a prize"", which refer to click-through advertisements. Interestingly, all of the eleven girls who took part in this stage were of the belief that the only form of advertising on these sites was the various banner advertisements which surround the sign-in page and their profile pages.

As part of the participant observation stage, an in-depth examination of the profile pages of these eleven participants was conducted. The presence of what the focus group participants identified as online advertising, namely banner advertisements and click-through advertisements was indeed observed. Also, a variety of banner advertisements was displayed on the top of the each user's home page and profile page. These banner advertisements ranged from fast food chains and soft drinks, to awareness campaigns for social issues. However, the participants in the follow-up interviews (after the observation stage) were oblivious to the specific content of any of the advertisements that appeared on the Bebo pages and upon recognising the content as advertising, they ignored it completely. For example, in a discussion with Kim (13 years) and using her Bebo profile as a prompt, the interviewer enquired about advertising that appears on social networking sites:

Interviewer: Have you ever seen advertisements on Bebo?

Kim: $\quad$ Yeah, there are a few on there. 
Interviewer: What are they like?

Kim: [pointing to her Bebo home page on the computer screen] Well, there is one [identifies a banner advertisement on the top of the page for a fast food franchise]. They come up like that on the top of my profile page as well.

Interviewer: Is that how all the advertisements look like on Bebo?

Kim: $\quad$ Yeah, I don't think I have seen any others.

However, as Kim made this statement, it was observed that two highlighted commercial profile pages on her home page, were listed as 'sponsored'. These two pages related to an energy awareness campaign and a message about a well-known soft drink brand. However, neither of these was identified as advertising or commercial content by Kim.

Therefore, whilst the participants purported to be fully aware of the various types of advertising, it became clear that they were not actually au fait with these types when exposed to them. This reinforces a recently expressed concern in the literature that younger consumers may have difficulty identifying the nature of advertising in the context of a non-traditional medium in comparison to traditional media such as television (Owen, Lewis, Auty and Buijzen, 2013; Rozendaal, Buijzen and Valkenburg, 2011).

\section{Ambivalence and Negativity towards Advertising}

The participants were then asked whether or not they viewed such forms of advertisements to be effective. Interestingly, all of the girls took the stance that the advertisements on social 
networking sites were ineffective, often irrelevant and something to which they never really paid attention. For example, Lisa (14 years) commented:

Well, I don't really pay attention to them [banner and pop-up advertisements on social networking sites], I mean, maybe someone would be interested in what they are selling and look at them, but for me, I think they [the companies] are wasting their money.

Additionally, Katie (13 years) outlined "I've seen the ads that flash at the top of my profile page and on the sign-in page, but I really don't think anyone pays any attention to them”. Similarly in one focus group, the girls (all aged 13 years) indicated that they did not view advertisements on social networking sites as being effective.

Interviewer: Have you ever seen ads on social networking sites?

Amy: $\quad$ Those long ones? Yeah, I've seen them at the top of my sign-in page.

Keira: Oh yeah, I've seen them too. They are on the home page as well.

Interviewer: What do you think of them?

Amy: I don't really think too much about them. I don't really bother with them.

Julianne: I think they are annoying. Does anyone actually look at them?

Keira: $\quad$ No, I don’t think anyone does. I think they are pointless really.

Therefore, it was observed that when the various advertising formats were identified and discussed in both the focus groups and the interviews, the girls did not pay substantial attention to them, for reasons relating to perceived irrelevance or annoyance. Such opinions about pop up and banner advertising on social networking sites are in line with the opinions 
expressed by the teenagers in Kelly, Kerr and Drennan's (2010) study, who also ignored the ads and were of the opinion that such advertising practices were not effective.

\section{Unintentional Brand Ambassadors}

The participant observation stage of the study indicates that the girls included various forms of branded or commercial content on their profile page to a very large degree. This is a particular function that Bebo offered the girls, and this facility substantially illustrated the girls' use of, and interaction with branded content. For example, unlike Facebook, Bebo allowed users to design or customise their own profile page back-drop.

This was evident in Lisa's (14 years) Bebo profile, where she proudly displayed a branded Coca-Cola skin (the design component of a user's profile) as her profile page background. She explained her brand choice thus:

Lisa: It is a mainly black background with red writing on it and some pictures on it... The pictures are of bottles of Coca-Cola, but that is because it is a special Coca-Cola skin.

Interviewer: Why did you pick a Coca-Cola background?

Lisa: Well, I really like Coca-Cola, I have a bottle almost every day. And I think the background looks really cool.

Interviewer: Do you think Coca-Cola is a cool brand in general?

Lisa: $\quad$ Yeah, I think so. I mean everyone likes Coca-Cola and they always have cool ads.

Interviewer: Did you purposely go and search for a Coca-Cola branded skin?

Lisa: No, I was looking at someone's profile and saw they had it as a background and I liked it, so I made it my background too. 
According to DuBois Gelb and Rangarajan (2014), a brand ambassador is an envoy who represents the brand to customers, potential customers and the public at large. Elsewhere, Groeger and Buttle (2014, p.21) suggest that companies seek to create brand ambassadors who will "spread the word about their products". Both perspectives on the nature of a brand ambassador perfectly describe Lisa's role in the present example. By selecting the branded Coca-Cola skin as her Bebo profile background, Lisa (14 years) was not only making a visible statement of her preference for the brand itself, but also offering the Coca-Cola brand valuable exposure among her network of friends and peers. Moreover, Lisa noted that she acquired this background when she saw it displayed on the page of one of her peers, which denotes an element of social acceptance of the Coca-Cola brand, establishing it as a cool and desirable brand with strong social capital.

Elsewhere, it was observed that a further participant, Sandra (14 years) was not only affiliating herself with a particular brand or product, but had actually posted a video of one of the brand's television advertisements on her profile page during the three month period of the participant observation. The advertisement in question, on Sandra's profile page was an advertisement for the Cadbury's Dairy Milk Chocolate brand.

Interviewer: Why did you choose to play a Cadbury's Dairy Milk ad on your profile?

Sandra: I like that ad, it's funny and I just wanted to put it on my profile for people to see.

Interviewer: So, you are putting an ad on your profile that plays when people open up your page. Do you think that you are helping Cadbury's advertise their Dairy Milk product?

Sandra: No, of course I'm not advertising for them. It's just funny. 
However, it is suggested that the girls are inadvertently acting as brand ambassadors on social networking sites. In the example above, Sandra professes to not promoting the Cadbury's brand, but in practice, she is not only affiliating herself to the brand, but is also actively promoting it to others visiting her profile page. A further example of brand affiliation through social networking sites is provided by Donna (14 years) who included pictures of a number of brands on her profile page, such as Converse, Hollister and Ugg. Donna also referred to her liking for taking online quizzes about a variety of areas, ranging from her knowledge of soap opera characters to brand knowledge. The results of these quizzes are displayed on the individual's profile page so that others, such as friends and peers can see the results generated from taking a particular quiz and, in some cases, the answers given by the participant. As such, some participants are conscious that these quizzes present an ideal image or persona. For example, Donna admitted to taking some quizzes a number of times in order to manipulate or control the result displayed on her profile page.

Donna:Well there is a quiz on my page that is called 'What shoe are you?' I'm a big fan of Converse shoes and I wanted the quiz to show that on my page, so I took the quiz a couple of times to make sure that the result showed Converse.... I love Converse shoes, they're cool and really, it is just a bit of fun.

During the discussion with Donna, the interviewer questioned whether the incorporation of such branded content on her profile page equated to promoting these brands to her friends. In response, Donna (14 years) replied:

No, I don't think so. I just like these brands. I like their stuff and like to wear them so that is why I have them on my profile page. Not because I'm promoting the brands to my friends. 
For Donna, the inclusion of the various brands and logos were simply expressions of her personality, style and brand preference and she did not perceive that this could be interpreted as brand promotion to her peers. During the three-month observation of the participants' social networking profiles, it was noted all eleven participants were friends with, or fans of, at least one brand. Lifestyle brands such as Ugg, Converse, GHD (hair straighteners) and Playboy, together with bands, movies and television shows, held strong appeal for the participants. The interviewer discussed with Ruth (14 years) her friending of the Ugg, GHD and Abercrombie and Fitch brands:

Interviewer: I see here [pointing at the computer screen] that you have joined a number of groups showing you are a fan of certain brands.

Ruth: $\quad$ Yeah, I've joined the Ugg group, the GHD [brand of hair straighteners] group and the Abercrombie and Fitch [clothing] group.

Interviewer: Why did you pick these brands?

Ruth: Well, I like these brands. They are cool and I suppose, fashionable.

Interviewer: Do you own these brands?

Ruth: $\quad$ I share a GHD with my sister, because they are kind of expensive. I don't own a pair of real Uggs yet [laughs], but I'm hoping to save up for a pair soon. I don't have any Abercrombie clothes either...but some of my friends have them because they got them in London or America, and I think they are lovely.

Ruth's use of words such as 'cool', 'fashionable' and her reference to her friends owning these brands are therefore clearly indicative of how the girls were using certain brands on 
their SNS pages for social and aspirational reasons in that these brands have been given a stamp of approval by their peers.

Moreover, many of the participants included references to the Playboy brand on their profile pages, a brand which is targeted at adult consumers. However, Catherine (13 years) stated: No, I don't think that Playboy is an adult brand. I mean, I know about the magazines and the Playboy mansion and stuff and yeah that is supposed to be for adults but the Playboy stuff [branded products], like the watches and the clothes and the Playboy duvet covers [laughs] is all for teenage girls. I love them and so do all my friends but there is no way that any of my sisters [all in their 20's] would wear any of the Playboy stuff because they think it [the Playboy brand] is too young for them.

As such, one of the primary findings from this research is that these SNS users are employing brands or commercial messages as a form of self-expression, seeking to create an ideal image of themselves by association with a particular brand, regardless of whether they are actually consumers of the brand or are members of the brand's target market. Stern (2008) notes that as young consumers move through adolescence, they begin to question and deconstruct how they view themselves and how they are viewed by others. Furthermore, they use this period of transition in their lives to experiment with various aspects of their lives such as their image, identity, brand preference and what they think is socially acceptable (Boyd, 2007; Drake-Bridges and Burgess, 2010). Therefore with regard to the participants in the present study, it is unsurprising that they would embrace a medium that allows them to literally "type oneself into being" (Sundén, 2003, p.3).

However, what they view as sharing socially acceptable branded content with each other, could also be construed as unknowingly acting as brand ambassadors. Their awareness of 
advertising formats and their view of such formats as being ineffective, is accompanied by a lack of savoir faire that their behaviour also constitutes a form of peer-to-peer marketing. Even when probed about this possibility, they proclaimed their disagreement, and again reiterated their view that their sharing of content was for personal and social reasons, and could not be construed as acting as informal brand promoters. This suggests that the participants have not recognised or developed an understanding of the brand owner's strategy, namely the provision of engaging content for consumption, such as news updates, competitions, videos and games (Barger and Labrecque, 2013), and also for users to share and indeed generate their own positive brand-related content (Vernette and Hamdi-Kidar, 2013). The participants can articulate their motivations for sharing such content with their peers, but they do not view their actions as a means of generating earned media, or word-ofmouth (Wasserman, 2013) for the brand.

\section{The Online Brand Communications (OBC) Literacy Framework}

This study has illustrated that the participants are not just being exposed to traditional forms of online advertising within SNS, but that there are other more subtle and immersive means by which brand owners can promote their brand. An example would be the provision of entertaining brand-related content that users then share with each other. Therefore, these SNS users are exposed to far more commercial messaging through their social networking interactions than through traditional forms of media. This is largely due to users actively friending and 'liking' brands, companies or products, which in turn, affords companies an opportunity to communicate at will with their consumers and target market. In essence, SNS users are serving to generate earned media activity by promoting the brand in this way (Stephen and Galak, 2012). However, their ability to recognise commercial content is of concern. For example, the potential for a brand page on a SNS, such as Facebook, to be 
recognised as a form of advertising for a brand (Campbell, Cohen and Ma, 2014) was not identified by the participants.

Therefore, the authors contend that the traditional conceptualisation of advertising literacy needs to be revisited to take into account the contemporary online environment where the nature of commercial messaging is no longer primarily in the form of paid media (e.g. advertising) but is also being complemented by the availability of owned and earned media activities which are available to marketers.

Accordingly, the authors propose the Online Brand Communications (OBC) literacy framework as a basis for exploring children's commercial literacy in SNS, as well as other online platforms such as brand communities and advergames. The authors define OBC in terms of the various online platforms and conduits by which brand messaging is communicated. For example, brand messaging can originate from, and be communicated by the brand owner by way of the placement of creative and compelling content across paid media. However, online consumers can also act as message creators, for example, by way of generating their own ideas, content and contribution to brand meaning and also as brand ambassadors, as was evident in this study. The OBC framework adopts the paid, owned and earned media perspective on the contemporary marketing communications environment, which has been widely accepted by both academics and practitioners (e.g. Basney, 2014; Stephen and Galak, 2012; Corcoran, 2009). Table 1 illustrates the types, formats and manifestations that online brand communications, targeted at children, can assume. 


\section{TABLE 1: HOW ONLINE BRAND COMMUNICATIONS OCCUR}

Media type Formats include:

Paid

display / banner advertising search advertising paid influencers (e.g. incentivised bloggers)

Owned

website microsite, advergames brand community brand blog SNS page / account mobile app

Earned

any marketer activities that encourages consumers to share/ engage in word-of-mouth page

(i.e. sharing activities via SNS, blogs, forums, email)

\section{Manifestations in the present study}

banner / pop-up ads in SNS

brands on Facebook and Bebo which are followed by the participants

- brand ambassadors - using branded content to present personal profile pages

- sharing a link to an ad on one's profile

- posting pictures of preferred brand

Source: media types and formats adapted from: Stephen and Galak, 2012; Forrester Research, 2009. OBC concept and manifestations developed by the authors.

The purpose of the OBC literacy framework is to illustrate the nature and form that childtargeted brand communications can take in the online environment. What both paid and 
owned media have in common is that the brand owner invests time, creativity and/or money in actively drawing attention to their brand. It follows that this should in theory, facilitate the development of advertising literacy in recipients of such messaging. However, earned media refers to the word of mouth that accrues when a user converses and shares content about the brand (Stephen and Galak, 2012). Therefore, commercial content on SNS may be the direct result of network members sharing brand-related information. This could involve the sharing of brand-related videos or advertisements via their profile page, as well as using their page to share information about a product or brand they have just purchased, or to share positive or negative brand-related experiences (e.g. Muntinga, Moorman and Smit, 2011).

As was evident in the present study, the participants are using preferred brands as a form of expression, and in doing so, they are also contributing to the promotion of these brands in the form of earned media (Wasserman, 2013). Therefore, for a young consumer to develop OBC literacy, he/she needs to develop an understanding that brand messaging in an online environment can be created and communicated by a brand owner as well as third parties such as consumers.

In this respect, the authors propose five components of a child's online brand communications literacy, with respect to the paid, owned and earned media activities of a brand owner, as outlined in Table 2.

TABLE 2: THE ONLINE BRAND COMMUNICATIONS LITERACY FRAMEWORK

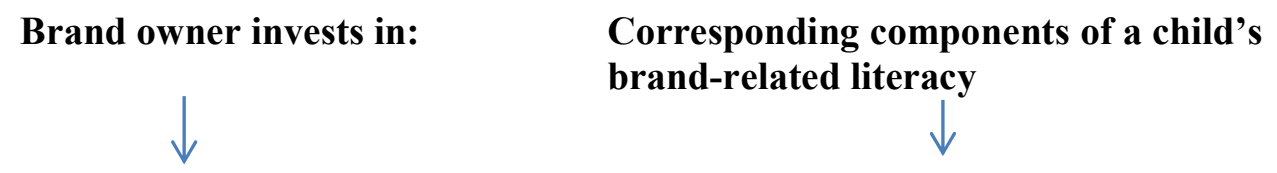


Paid media / content

Owned media / content

Earned media / content
Recognition of the range and nature of online platforms available to the brand owner

Appreciation of the brand owner's objectives, ranging from consumer-brand engagement to sales objectives

Understanding that brand-related content can originate from other consumers, as well as from the brand owner

Understanding that word-of-mouth (WOM) relating to a brand can be encouraged and incentivised by brand owner

Understanding that brand-related content can be presented by the brand owner, and appropriated by third parties, such as consumers, for personal, social and commercial reasons

To expand upon Table 2, the OBC literacy framework proposes five facilities that should be encouraged in children when navigating commercial content online:

1. Developing a child's recognition of the nature and range of online brand promotion (e.g. a brand's presence in a virtual community, advergame, microblog or SNS). This understanding acknowledges that brand communications are broader than merely taking the forms of online advertisements.

2. Developing a child's understanding that brand-related content can originate from the brand (e.g. a brand's SNS page or YouTube channel) as well as being created, shared and disseminated by customers (e.g. 'liking' a brand on Facebook, posting a customer suggestion on a company's 'customer ideas' webpage).

3. Developing an understanding that the brand owner may pursue a range of objectives that may not be obviously linked with selling intent. These objectives could be to encourage consumer-brand engagement, to foster message virality (e.g. sharing of an advertisement), or to generate insights into consumer behaviour (e.g. Proctor and Gamble’s beinggirl.com website). 
4. Fostering a child's understanding that earned media, namely, brand-related, word-ofmouth communications can be encouraged and often financially incentivised by the brand owner.

5. Developing a child's understanding that brand meaning can be presented by the brand owner, and appropriated by the online user, according to the latter's personal and social motivations. For example, it was evident in this study that the participants affiliated themselves with brands that assisted in personal identity management and also accessing peer acceptance.

Essentially, the OBC literacy framework seeks to encompass the breadth of commercial content that children are being exposed to online and to also acknowledge the convergence between the two marketer-driven forms of content (paid and owned) and consumerfacilitated content (earned media). The extant literature on advertising literacy has focused on traditional forms of advertising where distinct ingredients such as recognition of advertising as a genre, recognition of the advertiser as the message source, understanding of the audience as an advertising target and understanding of the selling intent of advertising can be identified (Rozendaal, Lapierre, Van Reijmersdal and Buijzen, 2011). However, the afore-mentioned move from standard advertising to brand story-telling in an online environment, means that advertising as a genre is changing, the message source may be indeed be other consumers, the audience may be instrumental in meaning creation, as opposed to being targets, and the intent of such communications may be to encourage non-sales outcomes, such as message virality. As such, the OBC literacy framework is presented as an alternative to the traditional conceptualisation of advertising literacy, which arguably is not always 'fit for purpose' in the online environment where overt forms of advertising paid for by the marketer, are no longer the only way to promote a brand. 


\section{Conclusions and Future Research}

This is the first research study to explore children's advertising literacy in a SNS context. It responds to calls for further research into children's exposure to, and responses to advertising in an online context (Connell, Brucks and Nielsen, 2014; Freeman and Shapiro, 2014). The study reveals that there is cause for concern. Participants tend to equate online advertising with banner advertisements, click-through advertisements and pop-up advertisements, yet they do not view branded social networking pages, video-sharing websites or company websites as forms of commercial communications. This points to low levels of advertising literacy since a key component of advertising literacy is the ability to understand the commercial agenda of the marketer (Moses and Baldwin, 2005). The participants had a very narrow view of what constituted commercial content in a social networking environment, and more compellingly, they were unaware of the behavioural changes that advertisers seek to bring about in them, such as brand-related, sharing behaviours. As such, they are potentially vulnerable to commercial and other exploitation as they do not appear to have developed what Connell, Brucks and Nielsen $(2014$, p.120) refer to as 'executive functioning skills' in terms of recognising and processing the variety of approaches that brand owners are using to target them.

Indeed, even when it was suggested to them that their friending of brands and sharing of branded content with their peers conveyed upon them the role of brand ambassadors, they reiterated their view that they did not conceive such interaction with brands or products as a form of advertising or promotion. Instead, they identify this practice of brand-sharing in one context, solely as a means of making personal statements of taste. The emergence of young 
SNS users unwittingly or unknowingly acting as brand ambassadors or brand promoters (i.e. earned media) has not been explored in the literature to date. In the context of Ritson and Elliott's (1995) perspective on advertising literacy, namely one's ability to co-create and act upon advertising's multifarious meanings, it would appear that many of the girls in this study, have not developed this ability. Instead they view advertising narrowly in terms of (a) content that they do not pay attention to, for example, for perceived reasons of irrelevance or mild irritation, or else (b) content that they find to be interesting and aspirational and therefore suitable for sharing with friends. What they may not realise is that marketers deliberately engage in developing content (as in (b) above) with a view to encouraging such 'COBRAs' or consumers' online brand-related activities, to return to a phrase developed by Muntinga, Moorman and Smit, (2011, p.2). Thus, the girls did not indicate an implicit or explicit awareness that they were acting as a source of word-of-mouth or an unofficial promoter of these brands. As such, they have not met a key criterion of commercial literacy, namely an ability to understand the commercial agenda of the marketer (Buckingham, 1993; Moses and Baldwin, 2005).

This conclusion therefore directly speaks to the theme of the present special issue of the European Journal of Marketing, namely the impact of marketing on children's well-being in a digital age. The extent to which commercial messages can be seamlessly integrated or embedded into online content, as observed in this study, highlights the potential vulnerability of these participants. Consumer vulnerability has been defined as "a state of powerlessness that arises from an imbalance in marketplace interactions or from the consumption of marketing messages and products" (Baker, Gentry and Rittenburg, 2005, p.134). In the present study, the imbalance in marketplace interactions and the accompanying erosion of power may arise when the immersive, entertaining and compelling nature of online content 
serves to eclipse the commercial agenda of the brand owner, in the eyes of the young consumer. Therefore, for all of the advantages that the internet can offer young users, this study articulates a concern that children's commercial well-being in the online landscape may be challenged if they do not develop and deploy a critical awareness of online brand communications.

Notwithstanding, this study has a number of limitations to be considered. Firstly, the study was based in Ireland and therefore, the findings are specific to this location. For example, a wider SNS study in other countries might yield different findings on the basis of, for example, different advertising and marketing regulations in place in those countries. Furthermore, the sample was limited to females aged 12 to 14 years old, which would provide opportunities for future exploration of both male and female SNS users, in different age-groups.

In terms of areas for further research, there remains a large research gap concerning children's awareness of, and ability to critique the use of SNS by commercial organisations, for commercial purposes. Therefore, it is suggested that future research would continue to explore children's perspectives in this area. For example, do young users realise that they are being presented with commercially-sponsored content with a view to being encouraged to share and promote this content to others? What are their views on being targeted as potential brand ambassadors in this respect?

From a consumer socialisation perspective, young consumers in the age grouping of 11 to 16 years have traditionally been viewed as being more reflective and sophisticated than younger children in terms of their commercial information processing skills (Roedder John, 1999), 
and their deeper knowledge and understanding of advertising (Boush, Friestad and Rose, 1994). However, this knowledgeable, reflective and sophisticated approach to understanding traditional advertising has not prevailed in the present research which focused on young consumers aged 12 to 14 years. As per the note of caution sounded by Owen, Lewis, Auty and Buijzen (2013), the authors would also query whether this age categorisation continues to be valid. Owen, Lewis, Auty and Buijzen's study of six to ten year old children and the present study of 12-14 year olds, have both indicated that the two sets of young consumers had difficulty in recognising commercial messages, in non-traditional channels. This therefore suggests that the traditional hallmarks of commercial literacy in a child, namely being able to discern between advertising and other media content, and understanding the advertiser's intent, do not neatly translate into the online environment. Further research is therefore necessary in this area if policymakers are to regulate advertising and marketing, based on an up-to-date understanding of children's interaction with non-traditional marketing channels, as opposed to regulating the online, commercial environment on the basis of children's offline advertising literacy.

Indeed the potential for the online environment to offer anonymity and lack of disclosure may militate against the development of advertising literacy, as it is currently conceptualised in the literature. Consider the phenomenon of stealth marketing which relates to the employment of secretive practices which do not reveal an underlying relationship with the company that crafts or provides the message (Martin and Smith, 2008). This means that in some cases, recipients of such content may not be provided with two key protection mechanisms - persuasion knowledge and agent knowledge (Obermiller, Spangenberg and MacLachlan, 2005; Friestad and Wright, 1994). Research to date on children's understanding of advertising has been predicated on exploring such responses against the context of 
traditional advertising platforms, where the sender and nature of the message are potentially discernible. Future research could explore the relative presence and nature of literacy amongst younger consumers with regard to the use of covert, online platforms, e.g. the creation of sponsored blogs that fail to disclose financial arrangements with interested companies. Equally, this has implications for public policy in that further attention needs to be given to how children are being educated about the range of advertising techniques and marketing formats that may be (a) deployed in an overt or covert manner and (b) used in both online and offline environments.

The Online Brand Communications (OBC) literacy framework seeks to reflect how the merging of boundaries between paid, owned and earned media has accompanying implications for merging the voices of brand owners and consumers. This means that traditional advertising literacy skills such as recognition and appreciation of advertising tactics and goals (Connell, Brucks and Nielsen, 2014) can be negated or militated against in a SNS context where the delineation between paid, owned, and earned media may not be clear to the child consumer. Hence, there is a pressing requirement for a new conceptualisation of advertising literacy in an online context which is informed by the increasing convergence of traditional online advertising and other forms of online brand content.

\section{References}

American Academy of Child and Adolescent Psychiatry (2011), “Children and social networking", available at 
http://www.aacap.org/AACAP/Families_and_Youth/Facts_for_Families/Facts_for_Families Pages/Children_and_Social_Networking_100.aspx (accessed 15 December 15, 2014).

An, S. and Kang, H. (2013), "Do online ad breaks clearly tell kids that advergames are advertisements that intend to sell things?" International Journal of Advertising, Vol. 32 No. 4, pp. 655-678. DOI: 10.2501/IJA-33-3-509-532

An. S., Jin, H.S. and Park, E.H. (2014), “Children's advertising literacy for advergames: Perceptions of the game as advertising" Journal of Advertising, Vol. 43 No. 1, pp. 63-72. DOI: 10.1080/00913367.2013.795123.

Anderson, L.B. and McCabe, D. (2012), "A co-constructed world: adolescent self socialization

on the Internet”, Journal of Public Policy \& Marketing, 31 (2), pp. 240-253.

Baker, S.W., Gentry, J.W. and Rittenburg, T.L. (2005), "Understanding the domain of consumer vulnerability”, Journal of Macromarketing, Vol. 25 No. 2, pp. 128-139.

DOI: $10.1177 / 0276146705280622$

Barger, V.A. and Labrecque, L.I. (2013), “An integrated marketing communications perspective on social media metrics", International Journal of Integrated Marketing Communications, Vol. 5 No. 1, pp. 64-76.

Basney, B. (2014), “Brands as publisher: using content and paid media to fuel a brand Transformation", Journal of Brand Strategy, Vol. 3 No. 2, pp. 101-110.

Boush, D.M., Friestad, M. and Rose, G.M. (1994), “Adolescent skepticism towards TV advertising and knowledge of advertiser tactics", Journal of Consumer Research, Vol. 21 No. 1, pp. 165-175.

Boyd, D. (2007), "Why youth (heart) social networking sites: the role of networked publics in teenage social life", in Buckingham, D., (Ed.), (2008), Youth, Identity and Digital Media, 119-142, Cambridge, MIT Press. 
Buckingham, D. (1993), Children Talking Television: The Making of Television Literacy, London, Falmer.

Campbell, C., Cohen, J. and Ma, J. (2014), “Advertisements just aren't advertisements anymore - a new typology for evolving forms of online 'advertising' ', Journal of Advertising Research, Vol. 54 No. 1, pp. 7-10. DOI: 10.2501/JAR-54-1-007-010. Carson, D., Gilmore, A., Perry, C. and Gronhaug, K. (2001), Qualitative Marketing Research, London, Sage Publications.

Chaffey, D. (2012), “The difference between paid, owned and earned media - 5 viewpoints”, available at http://www.smartinsights.com/digital-marketing-strategy/customer-acquisition-strategy/new-

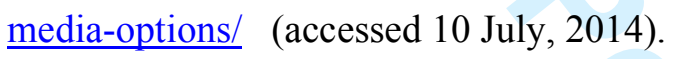

Cheyne, A.D., Dorfman, L., Bukofzer, E. and Harris, J.L. (2013), "Marketing sugary cereals to children in the digital age: a content analysis of 17 child-targeted websites", Journal of Health Communications, Vol. 18 No. 5, pp. 563-582. doi: 10.1080/10810730.2012.743622 Clarke, B., Goodchild, M. and Harrison, A. (2010), "The digital world of children and young adolescents: children's emotional engagement with digital media”, ESOMAR Congress Odyssey, Athens.

Clarke, B. and Svanaes, S. (2012), "Digital marketing and advertising to children: a literature Review" (Advertising Education Forum), available at http://www.aeforum.org/gallery/8612144.pdf. (accessed 27 June, 2014).

Connell, P.M., Brucks, M. and Nielsen, J.H. (2014), "How childhood advertising exposure can create biased product evaluation that persist into adulthood", Journal of Consumer Research, Vol. 41 (June), pp. 119-134. DOI: 10.1086/675218.

Corcoran, S. (2009), "Defining earned, owned and paid media", available at http://blogs.forrester.com/interactive marketing/2009/12/defining-earned-owned-and 
paid-media.html (accessed 18 December, 2014).

Coughlan, S. (2010), "Facebook is a major influence on girls, say survey", $B B C$

News (18 May), available at http://www.bbc.co.uk/news/10121931 (accessed 10 July, 2014).

Dahl, S., Eagle, L. and Báez, C. (2009), “Analyzing advergames: active diversions or actually deception. An exploratory study of online advergames content", Young Consumers, Vol. 10 No. 1, pp. 46-59.

Denzin, N. and Lincoln, Y. (1998), Collecting and Interpreting Qualitative Materials, Thousand Oaks, CA, Sage Publications.

Diffley, S., Kearns, J., Bennett, W. and Kawalek, P. (2011), “Consumer behaviour in social networking sites: implications for marketers", Irish Journal of Management, Vol. 30 No. 2, pp. 47-65.

Drake-Bridges, E. and Burgess, B. (2010), "Personal preferences of tween shoppers", Journal of Fashion Marketing and Management, Vol. 14 No. 4, pp. 624-633.

DuBois Gelb, B. and Rangarajan, D. (2014), "Employee contributions to brand equity", California Management Review. Vol. 56 No. 2, pp. 95-112. DOI: 10.1525/cmr.2014.56.2.95.

Eagle, L. (2007), “Commercial media literacy”, Journal of Advertising, Vol. 36 No. 2, pp. 101-110.

ESOMAR (1999), “ESOMAR world research codes and guidelines: interviewing children and young people", available at http://www.esomar.org/uploads/pdf/ESOMAR_CodesandGuidelines_IntervewingChilden.pdf (accessed 13 May, 2014).

Facebook (2015), "Stats" available at http://newsroom.fb.com/company-info/ (accessed 25 June 2015). 
Forrester (2009, December 16), "Defining earned, owned and paid media”, available at http://blogs.forrester.com/interactive_marketing/2009/12/defining-earned-owned-and-paidmedia.html (accessed 8 October, 2015).

Freeman, D. and Shapiro, S. (2014), “Tweens' knowledge of marketing tactics - sceptical beyond their years", Journal of Advertising Research, Vol. 54 No. 1, pp. 44-55. DOI: 10.2501/JAR-54-1044-055.

Friestad, M. and Wright, P. (1994), “The persuasion knowledge model: how people cope with persuasion attempts”, Journal of Consumer Research, Vol. 21 No. 1, pp. 1-31.

Grimes, S.M. and Shade, L.R. (2005), “Neopian economies of play: children's cyberpets and online communities as immersive advertising in NeoPets.com", International Journal of Media and Cultural Politics, Vol. 1 No. 2, pp. 181-198. DOI: 10.1386/macp.1.2.181/1.

Groeger, L and Buttle, F. (2014), "Word-of-mouth marketing influence on offline and online communications: Evidence from case study research", Journal of Marketing

Communications, Vol. 20 Nos. 1-2, pp. 21-41, doi.org/10.1080/13527266.2013.797736

Kelly, L., Kerr, G. and Drennan, J. (2010), “Avoidance of advertising in social networking sites: the teenage perspective", Journal of Interactive Advertising, Vol. 10 No. 2, pp.16-27. Kerrane, B. and Hogg, M.K. (2013), “Shared or non-shared? Children's different consumer socialisation experiences within the family environment", European Journal of Marketing, Vol. 47 Nos. 3/4, pp. 506-524. DOI 10.1108/03090561311297436

Kvale, S. and Brinkmann, S. (2009), Interviews: Learning the Craft of Qualitative Research Interviewing, Second Edition, Thousand Oaks, CA, Sage Publications.

Lawlor, M-A. and Prothero, A. (2008), “Exploring children's understanding of television advertising - beyond the advertiser's perspective", European Journal of Marketing, Vol. 42 Nos. 11/12, pp. 1203-1223. DOI 10.1108/03090560810903646

Livingstone, S. and Helsper, E. J. (2006), "Does advertising literacy mediate the effects of 
advertising on children? A critical examination of two linked research literatures in relation to obesity and food choice", Journal of Communication, Vol. 56 No. 3, pp.560-584. Livingstone, S. and Brake, D.R. (2010), “On the rapid rise of social networking sites: new findings and policy implications", Children \& Society, Vol. 24 No. 1, pp.75-83.

DOI:10.1111/j.1099-0860.2009.00243.x

Livingstone, S., Ólafsson, K. and Staksrud, E. (2013), "Risky social networking practices among 'underage' users: lessons for evidence-based policy”, Journal of Computer-Mediated Communication, Vol. 18 No. 3, pp. 303-320.

Mallinckrodt, V. and Mizerski, D. (2007), “The effects of playing an advergame on young children's perceptions, preferences and requests", Journal of Advertising, Vol. 36 No. 2, pp. 87-100.

Market Research Society (2012), “MRS Guidelines for Online Research”, available at http://www.mrs.org.uk/pdf/2012-016\%20Online\%20Research\%20Guidelines.pdf (accessed 27 July, 2012).

Marshall, C. and Rossman, G.B. (2011), Designing Qualitative Research, Fifth Edition, Thousand Oaks, CA, Sage Publications.

Martin, K.D. and Smith, N.C. (2008), “Commercialising social interaction: the ethics of stealth marketing", Journal of Public Policy and Marketing, Vol. 27 No. 1, pp. 45-56.

Miles, M. B. and Huberman, A. M. (1994), Qualitative Data Analysis, Second Edition, Thousand Oaks, CA, Sage Publications.

Moore, E. S. and Rideout, V.J. (2007), “The online marketing of food to children; is it just fun and games?” Journal of Public Policy and Marketing, Vol. 26 No. 2, pp. 202-220. DOI: 10.1509/jppm.26.2.202.

Moses, L. J. and Baldwin, D. A. (2005), "What can the study of cognitive development reveal about children's ability to appreciate and cope with advertising?" Journal of Public 
Policy and Marketing, Vol. 24 No. 2, pp. 186-201. DOI: 10.1509/jppm.2005.24.2.186.

Muntinga, D. G., Moorman, M. and Smit, E. G. (2011), “Introducing COBRAs: Exploring motivations for brand-related social media use", International Journal of Advertising, Vol. 30 No. 1, pp. 2-23.

Nairn, A. and Fine, C. (2008), “Who's messing with my mind? The implications of dual process models for the ethics of advertising to children", International Journal of Advertising, Vol. 27 No. 3, pp. 447-470.

Nairn, A., Griffin, C. and Wicks, P.G. (2008), “Children's use of brand symbolism - a consumer culture theory approach", European Journal of Marketing, Vol. 42, Nos. 5/6, pp. 627-640. DOI 10.1108/03090560810862543

Nairn, A. and Hang, H. (2012), “Advergames: It's not child's play. A review of research”, (London: Family and Parenting Institute), available at http://www.agnesnairn.co.uk/policy reports/advergames-its-not-childs-play.pdf (accessed 15 December, 2014).

Newman, N. and Oates, C.J. (2014), "Parental mediation of food marketing communications aimed at children", International Journal of Advertising, Vol. 33 No. 3, pp. 579-598. DOI: 10.2501/IJA33-3 579-598.

Obermiller, C., Spangenberg, E.R. and MacLachlan, D.L. (2005), “Ad scepticism: The consequences of disbelief", Journal of Advertising, Vol. 34 No. 3, pp. 7-17.

Ofcom (2014), "Children and parents: media use and attitudes report”, available at http://stakeholders.ofcom.org.uk/binaries/research/media-literacy/media-use-attitudes 14/Childrens_2014_Report.pdf (accessed 8 October, 2015).

O’Neill, B., Grehan, S. and Ólafsson, K. (2011), "Risks and safety for children on the Internet: The Ireland report. LSE, London: EU Kids Online Survey", available at http://eprints.1se.ac.uk/46444/1/IrelandReport.pdf (accessed 23 July, 2014). 
O’Neill, B. and Dinh, T. (2012), “Social networking among Irish 9-16 year olds. EU Kids Online, Ireland. Digital Childhoods Working Paper Series No. 3”, available at http://www.dit.ie/cser/media/ditcser/digitalchildhoods/SNS\%20Report\%20June\%2028.pdf (accessed 17 December, 2014).

O’Sullivan, T. (2007), “Get MediaSmart $®$ : A critical discourse analysis of controversy around advertising to children in the UK", Consumption, Markets and Culture, Vol. 10 No. 3, pp. 293-314.

Owen. L, Lewis, C., Auty, S. and Buijzen, M. (2013), “Is children's understanding of nontraditional advertising comparable to their understanding of television advertising?" Journal of Public Policy and Marketing, Vol. 32 No. 2, pp. 195-206.

Panic, K., Cauberghe, V. and De Pelsmacker, P. (2013), “Comparing TV ads and advergames targeting children: the impact of persuasion knowledge on behavioural responses", Journal of Advertising, Vol. 42 Nos. 2-3, pp. 264-273. DOI: 10.1080/00913367.2013.774605.

Ritson, M. and Elliott, R. (1995), “Advertising literacy and the social signification of cultural Meaning”, European Advances in Consumer Research, Vol. 2, pp. 113-117.

Roedder, D. (1981) “Age differences in children's responses to television advertising: An information-processing approach", Journal of Consumer Research, Vol. 8 (September), pp. $144-153$

Roedder John, D. (1999), “Consumer socialisation of children: a retrospective look at twenty-five years of research", Journal of Consumer Research, Vol. 26 No. 3, pp. $183-213$.

Rozendaal, E., Buijzen, M. and Valkenburg, P. (2011), “Children’s understanding of advertiser's persuasive tactics”, International Journal of Advertising, Vol. 30 No. 2, pp. 329 350. DOI:10.2501/IJA-30-2-329-350.

Rozendaal, E., Lapierre, M.A., Van Reijmersdal, E.A. and Buijzen, M. (2011), 
"Reconsidering advertising literacy as a defense against advertising effects", Media Psychology, Vol. 14 No. 4, pp. 333-354. DOI: 10.1080/15213269.2011.620540.

Saunders, M., Lewis, P. and Thornhill, A. (2009), Research Methods for Business Students, Fifth Edition, Harlow, Pearson Education.

Schwartz, M.B., Kunkel, D. and DeLucia, S. (2013), "Food marketing to youth: pervasive, powerful and pernicious", Communication Research Trends, Vol. 32 No. 2, pp. 4-13.

Selman, R.L. (1980), The Growth of Interpersonal Understanding, New York, Sage.

Shin, W., Huh, J. and Faber, R.J. (2012), “Developmental antecedents to children's responses to online advertising”, International Journal of Advertising, Vol. 31 No. 4, pp. 719-740. DOI: 10.2501/IJA-31-4-719-740.

Stephen, A.T. and Galak, J. (2012), "The effects of traditional and social earned media on sales: a study of a microlending marketplace", Journal of Marketing Research, Vol. 49 No. 5, pp. 624-639.

Stern, S. (2008), "Producing sites, exploring identities: Youth online authorship". In Buckingham, D. (Ed.) (2008), Youth, Identity and Digital Media, Cambridge, MIT Press. Sundén, J. (2003), Material Virtualities, New York, Peter Lang. Verhellen, Y., Oates, C.J., De Pelsmacker, P. and Dens, N. (2014), “Children's responses to traditional versus hybrid advertising formats: the moderating role of persuasion knowledge". Journal of Consumer Policy, Vol. 37 No.1, pp235-255. DOI 10.1007/s10603-014 9257-1

Vernette, E. and Hamdi-Kidar, L. (2013), "Co-creation with consumers: who has the competence and wants to co-operate?" International Journal of Market Research, Vol. 55 No. 4, pp. 2-20.

Ward, S. (1974), “Consumer Socialization”, Journal of Consumer Research, Vol. 1 (September), pp. 1-14. 
Wasserman, T. (2013), "Is this article earned media? Depends where you got it from", available at http://mashable.com/2013/05/05/earned-media/ (accessed 5 June, 2014).

Willett, R. (2008) “Consumer citizens online: Structure, agency and gender in online participation" in Buckingham, D. (Ed.) (2008), Youth, Identity and Digital Media. Cambridge, MIT Press.

Willett, R. (2009), “As soon as you get on Bebo, you just go mad: young consumers and the discursive construction of teenagers online", Young Consumers, Vol. 10 No. 4, pp. 283-296.

Young, B. (2000), “The child's understanding of promotional communication”, International Journal of Advertising and Marketing to Children, Vol. 2 No. 3, pp. 191-203.

Young, B. (2003), “Does food advertising influence children's food choices? A critical review of some of the recent literature", International Journal of Advertising, Vol. 22 No. 4, pp. 441-459. 


1
2
3
4
5
6
7
8
9
10
11
12
13
14
15
16
17
18
19
20
21
22
23
24
25
26
27
28
29
30
31
32
33
34
35
36
37
38
39
40
41
42
43
44
59
50
56
57
48
59
51
53
50
5
5
5

14

15

16

18

19

20

22

23

25

26

27

29

30

32

33

34

35

36

37

39

40

41

42

44

45

46

47

48

49

51

52

53

54

55

57

58

60 \\ Page 43 of 51}

European Journal of Marketing

1
2
3

4

10

12

(1)

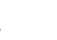

17

8

1

6

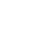

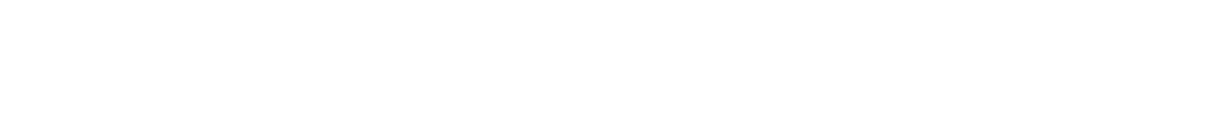




\section{Response to the reviewers' comments, queries and suggestions:}

We have highlighted in 'bold' below, all of the reviewers' comments, queries and suggestions and we have then given our responses to same in the accompanying, 'nonhighlighted' text. We have also indicated the relevant sections / pages where the changes have been made.

The explication of the special issue's theme in the context of this paper has also been addressed below, and in the revised paper.

$\underline{\text { Response to Research Methodology comments and suggestions: }}$

Reviewer: 1

It would have been helpful to know how and on what basis the young people were selected for inclusion into the study and also the extent of their SNS use (e.g. were they all regular/frequent users, what was the length of time they had been users etc.). How were they recruited? (I note the research was conducted in a school and a club setting but is this where the participants were recruited and why were these sites chosen?).

Reviewer: 2

How were the research participants recruited? In what part of Ireland was the research conducted? Could the participants be considered to be typical of the age group in general or is this not relevant for the research conducted?

What was the composition of the various focus groups - separate groups of 12-, 13- and 14-year-olds or mixed? What are the potential implications of decisions made?

\section{Reporting of findings}

Considering that the paper reports research conducted with an age span of 12-14 yearolds, the discussion does not offer any indication that there might have been differences between the various ages. There can be quite a difference between a 14-year-old and a 12-year-old, so some reflection in relation to any differences discerned in relation to the two research objectives this would be valuable.

In answer to the above, the following clarification and detail has been added (see Pages 1112).

With regard to the school-based research, the girls were in the same year (i.e. first year) in an all-girls secondary school in the south of Ireland. The girls were mostly aged 13-14 years, (three of the girls were aged 12 years), therefore leading to a mix of 12-14 year olds in the focus group discussions. The selection of these first-year school pupils was also informed by their transition from primary to secondary school which resulted in the girls being in a new social environment where their quest to make new friends and retain old friends, could 
potentially drive their use of social networking sites. One of the authors had previously worked in the school as a substitute teacher and also as a member of staff in the sports club. This was therefore helpful in gaining accessing to these two settings and in the case of the sports club, she was already known to the participants, thus facilitating further rapport in the research setting. All of the girls were regular online users, citing video-sharing websites (e.g. YouTube), online auction sites (e.g. eBay) and SNS (i.e. Bebo and Facebook) as their preferred online platforms. It should be noted that whilst Bebo was the more popular SNS amongst the sample, eight of the girls (either aged 13 or 14 years old) were Facebook users.

It was good to see reference to ethical considerations. Although implied, I am assuming that informed consent was sought? I would also be interested to know how ethical issues were addressed around policies/guidelines for dealing with any observed unsafe activities/posts etc. on SNS during the Participant Observation phase but realise this may be outside the scope of the paper.

The principle of informed consent has now been explicated on Page 11.

The authors' position upon commencing this research was that if any unsafe activities by the participants or the people with whom they were interacting on SNS, were observed or made known to the authors, they would bring this to the attention of relevant adults, i.e. schoolprincipal, teacher or parent. We feel that this position is already signalled (paragraph 1, Page 11), for example, by reference to seeking permission to conduct the research from parents, guardians and the children themselves, as well as conducting the study in a protected environment.

\section{Reviewer 1}

The description of the Participant Observation stage was a little unclear to me - were the participants actually observed while using SNS or were their profile pages accessed without them present? If the latter, then participant observation might not be the most appropriate label. It would also be helpful to know how frequently the girls' Bebo pages were accessed/studied over the three month period and if the girls knew when this was going to occur as this may have influenced their activities

\section{Reviewer 2}

A little more detail on the participant observation stage would be valuable. As this stage took place over a three-month period, did it use some type of systematic process?

In response to both reviewers, the discussion on Pages 12-13 has been developed, to include the following:

A defining feature of $\mathrm{PO}$ is its facility to allow the researcher to see and experience reality in a specific social setting, as seen and experienced by the participant (Marshall and Rossman, 
2011). Therefore, to complement the focus group discussions, the participant observation stage was included to give the authors access to, and experience of the girls' SNS activities. The second author invited the eleven participants in this phase of the research to add her as a friend on their SNS page. This action served a number of purposes, such as providing the authors with access to the girls' profiles, particularly if the girls had their profiles set to 'private'. The act of 'friending' reaffirmed the girls' consent to participate in the research and also meant that they would aware of when their pages were being accessed, i.e. when their Bebo activities were being observed. Throughout the participant observation stage, each participant's profile page, was observed on average, twice a week.

A little more detail about the interviews would also be appreciated - Some of the quotes (e.g. pg 14, lines 55-57) appeared to include discussion about Bebo home pages etc. so were all the interviews conducted with the computer/Bebo pages as prompts or were the findings of the Participant Observations discussed/used as prompts for the interview?

This is now detailed / clarified re: the specific section referred to above (on Page 15 of the revised manuscript).

We have also made similar clarification elsewhere e.g. Page 17-18 (Lisa' contribution); Page 19 (Sandra's contribution).

The results section starts off with a discussion about the focus groups but then states on page 14 "all of the eleven girls who took part in this stage" which is a little confusing. Were the quotes from Nicola and Ruth from the focus groups or the interviews?

This is now clarified at the end of Page 14 and start of Page 15.

It seems that the participant observations and interviews only focused on Bebo (not Facebook)? So was Facebook discussed in the focus groups (if not, then maybe only refer to Bebo throughout the paper)? If available, some background information about what SNS the participants used would have been good. I don't know this myself but is the advertising any different between on Facebook and Bebo?

The Research Methodology section identifies that the PO stage (and the follow-up interviews) observed Bebo activity only, whilst the focus groups explored Bebo and Facebook activities.

This is outlined at the end of Page 12; paragraph 2 on Page 13; paragraph 1, page 14. 
Just a few very minor typos/omissions/edits I noted:

All of the following changes / corrections have been made:

1. Page 2, line 17 - need an accent on Baez

2. Page 2, lines 30-31 - this would perhaps read better as "Children's recognition and understanding of how ..."

3. Page 3, line 3 - definition of advergames would be helpful

4. Page 4, lines 24-26 - use of the word latter seems out of place - I am not sure what the latter refers to in the previous sentence

5. Page 5, line 5 de Pelsmacker - has a capital for De elsewhere throughout the paper (also on page 7) Also on page 7 line 29-30 it needs a space between DePelsmacker

6. Pages 6-7 - "For example, Freeman and Shapiro (2014) refer to a gap ...." - should this read "young people's awareness of, and coping strategies for, marketing practices ..."

7. Page 7 - lines 7-10 - the sentence beginning "Elsewhere Shin ..." this reads as if Shin, Huh and Faber highlight the gap that prevails so the reference to Clarke and Svanaes is confusing

8. Page 7 - Nairn, Griffin and Wicks - in references as Gaya Wicks

9. Page 7 - line 34 - is there a word missing after the word overall?

10. Page 8 - Livingstone and Brake (2010) is missing from the reference list

11. It would be good to note that pseudonyms were used perhaps after first participant quote.

12. Page 22 - line 18-19 - Vernette and Hamdi-Kidar - bracket and full stop are in bold

13. Forrester Research, 2009 is not in the reference list.

14. Fournier and Avery - is in the reference list but not in text

15. Table 2 - helpful to have WOM in full

16. et al used on page 30 but has not been used for any other references cited more than once?

17. Carson reference - Qualitative not in italics

Reviewer: 2 
The authors are recommended to address the following points:

Whilst the subject matter is of direct relevance to the special issue title of the European Journal of Marketing - the impact of marketing on children's well-being in a digital age - this has not been explored. An explicit discussion is recommended whereby the relevance of the paper is made clear.

Page 3 introduces the special issue theme into the overall context of the paper as follows:

The theme of this special issue (SI) of the European Journal of Marketing pertains to the impact of marketing on children's well-being in a digital age.

This section then proceeds to relate well-being to the concept of vulnerability.

Page 30 explicates the theme of the SI as follows:

This conclusion therefore directly speaks to the theme of the present special issue of the European Journal of Marketing, namely the impact of marketing on children's well-being in a digital age. The extent to which commercial messages can be seamlessly integrated or embedded into online content, as observed in this study, highlights the potential vulnerability of these participants. Consumer vulnerability has been defined as "a state of powerlessness that arises from an imbalance in marketplace interactions or from the consumption of marketing messages and products" (Baker, Gentry and Rittenburg, 2005, p.134). In the present study, the imbalance in marketplace interactions and the accompanying erosion of power may arise when the immersive, entertaining and compelling nature of online content serves to eclipse the commercial agenda of the brand owner, in the eyes of the child. Therefore, for all of the advantages that the internet can offer young users, this study articulates a concern that children's commercial well-being in the online landscape may be challenged if they do not develop and deploy a critical awareness of online brand communications.

\section{Reviewer 2:}

Research methodology

There are a number of questions that the paper would benefit from answering:

How were the research participants recruited? In what part of Ireland was the research conducted? Could the participants be considered to be typical of the age group in general or is this not relevant for the research conducted?

What was the composition of the various focus groups - separate groups of 12-, 13- and 14-year-olds or mixed? What are the potential implications of decisions made? 
All of these aspects were addressed on the first and second pages of this document, as Reviewer 1 had also identified similar points.

A little more detail on the participant observation stage would be valuable. As this stage took place over a three-month period, did it use some type of systematic process?

All of these aspects were addressed on the first and second pages of this document Reviewer 1 had also identified similar points.

\section{Reporting of findings}

Considering that the paper reports research conducted with an age span of 12-14 yearolds, the discussion does not offer any indication that there might have been differences between the various ages. There can be quite a difference between a 14-year-old and a 12-year-old, so some reflection in relation to any differences discerned in relation to the two research objectives this would be valuable.

All of these aspects were addressed on the first and second pages of this document Reviewer 1 had also identified similar points.

\section{Ethical considerations}

Given the current emphasis on ensuring that research conducted has had ethical clearance, was the project approved by a university ethics committee?

All ethical protocols of the institutions affiliated with this research were followed.

In considering the question above, it was felt that the existing discussion of the ethical issues was more comprehensive as it specifically refers to international organisations such as ESOMAR and the Market Research Society.

Given that in order to have a Facebook profile, users need to be aged 13, it is appropriate to query whether users of Facebook under the age of 13 took part in the study? The quotes included in the paper are all from participants aged 13 and 14. It seems that the discussion only refers to Bebop. Perhaps the authors should consider removing the references to Facebook altogether, as this SNS does not appear to be referred to in the discussion?

This has been clarified in the Research Methodology section of the paper. Specifically, eight of the girls were Facebook users and all were aged 13 or 14 years old.

Similarly, the RM section clarified that only three of the girls were aged 12 years, hence the prevalence of contributions in the 'discussion of findings' sections from participants, aged 13 and 14 years. 
Some further observations/recommendations:

Page 2, second paragraph: The Ofcom statistics cover a very wide age span. It would seem more appropriate to use figures directly comparable with those quoted for the US. The research reported in the paper deals with 12-14-year-olds. Figures for five-yearolds will skew the numbers downwards.

We returned to the Ofcom (2014) website and as reported therein, we have changed the statistic on Page 2 to read:

"in the UK, Ofcom (2014) identify that $67 \%$ of children, aged between 12-15 years of age, had an active SNS profile in 2013".

A minor observation: On page 9, line 10, it says "research with adult and young SNS users (aged 14-17). Could adults perhaps be removed from this sentence as they are not of interest to the paper? The reader may think that 17 -year-olds are considered 'young adults', which is probably not the case?

This change has been made in paragraph 1 , Page 9.

Page 14, line 7: "the eleven girls who took part in this stage" - It is not clear which stage of the research this refers to. The sentence should probably explicitly refer to the participant observation stage.

Reviewer 1 also made this observation and we provided our response above. The sentence has been changed (Page 14).

Throughout the paper: When listing a number of references within parentheses, the references need to be listed in a consistent, chronological order - either starting with the oldest paper and finishing with the paper with the most recent year of publication or the other way around.

We have checked all references, and the format consistently followed for multiple references, is to start with the most recent paper, ending with the oldest reference.

Page 18, first sentence: The format for providing a page reference is different from that used on page 7 , line 5 .

Groeger and Buttle's quote (on Page 18) is now presented as $(2014$, p.21) so as to be consistent with the previous quote on Page 7. 


\section{Reference list: Boyd's year of publication is 2007 in a book edited by Buckingham with a publication year of 2008 . Is this correct?}

Boyd's year of publication is correct.

Buckingham's text was published in paperback in Nov.'07 and in hard cover in Jan' 08, but we retained year of publication as 2008 .

This is because two other authors who are referenced in the paper, also have contributed to Buckingham's book and they refer to the year of the book's publication as 2008 .

\section{The following typographical errors have been found:}

All of these changes have been made.

Page 7, line 5: Remove the full stop after Faber.

Page 33, line 34: The word 'journal' needs to be in italics.

Page 36, line 3: There is a comma missing after (2013).

Page 39, line 38: The word 'journal' needs to be in italics.

Page 40, line 27: There needs to be a space between $\mathrm{pp}$. and the page numbers. 